\title{
Measures to Enhance Student Learning and Well-Being during the COVID-19 Pandemic: Perspectives of Students from a Historically Disadvantaged University
}

\author{
Mpsanyana Makgahlela ${ }^{1, *(\mathbb{D})}$, Tebogo M. Mothiba ${ }^{2} \mathbb{D}$, Jabu P. Mokwena ${ }^{1} \mathbb{D}$ and Peter Mphekgwana ${ }^{3}(\mathbb{D})$ \\ 1 Department of Psychology, University of Limpopo, Sovenga 0727, South Africa; jabu.mokwena@ul.ac.za \\ 2 Faculty of Health Sciences Executive Dean's office, University of Limpopo, Sovenga 0727, South Africa; \\ tebogo.mothiba@ul.ac.za \\ 3 Research Administration and Development, University of Limpopo, Polokwane 0700, South Africa; \\ peter.mphekgwana@ul.ac.za \\ * Correspondence: mpsanyana.makgahlela@ul.ac.za; Tel.: +27-15-268-3942
}

check for updates

Citation: Makgahlela, M.; Mothiba, T.M.; Mokwena, J.P.; Mphekgwana, P. Measures to Enhance Student Learning and Well-Being during the COVID-19 Pandemic: Perspectives of Students from a Historically Disadvantaged University. Educ. Sci. 2021, 11, 212. https://doi.org/ 10.3390/educsci11050212

Academic Editor: Eleanor Dommett

Received: 9 March 2021

Accepted: 29 March 2021

Published: 30 April 2021

Publisher's Note: MDPI stays neutral with regard to jurisdictional claims in published maps and institutional affiliations.

Copyright: (C) 2021 by the authors Licensee MDPI, Basel, Switzerland. This article is an open access article distributed under the terms and conditions of the Creative Commons Attribution (CC BY) license (https:// creativecommons.org/licenses/by/ $4.0 /)$.

\begin{abstract}
Since December 2019, the world population has been battling with the SARS-CoV-2 disease (COVID-2019) pandemic. The pandemic has continued to impact negatively on people's livelihoods and also on student's education. This qualitative study established from students in a previously disadvantaged university, their challenges and needs pursuant to the COVID-19 nationwide lockdown in South Africa. A total of 312 (male $=141$; female $=171$ ) registered students were conveniently sampled and completed an online survey questionnaire. Thematically analysed data revealed that student education and health have been impacted since the COVID-19 nationwide lockdown. Participants went on to recommend several measures which, if implemented, could improve their well-being and access to education. Study findings imply that students from previously disadvantaged universities, who in their majority are from impoverished rural communities, have been struggling to access remote learning due to amongst others, the lack of information and communication technology (ICT) devices and network connectivity problems. It, therefore, requires rural-based universities to work together with the government and the private sector and join hands in addressing student challenges and needs during the on-going lockdown in the country. This would be one way of ensuring that in spite of students' socioeconomic status, cultural location or background, their right to education is protected.
\end{abstract}

Keywords: COVID-19; coronavirus pandemic; e-learning; distance learning; institutions of higher learning

\section{Introduction}

Since December 2019, the world population has been battling with the SARS-CoV-2 disease (COVID-2019) pandemic [1]. SARS-CoV-2 is a new strain of coronavirus that has never been recorded in humans before, and it is responsible for an outbreak of respiratory illness [2]. The viral disease was first detected in Wuhan, China, in December 2019 [1]. Upon the World Health Organisation's (WHO) classification of the airborne disease as a Public Health Emergency of International Significance (PHEIC) at the end of February 2020, many countries, South Africa included, put in force nationwide lockdowns to curb the scourge of the pandemic [3]. No single country anticipated the sudden and disastrous impact of COVID-19. The pandemic has continued to impact many countries' economies, politics, social welfare, education and healthcare systems [4]. Most regrettable is that human lives have been lost at an alarming rate considering the pathophysiology of COVID-19. The physical and psychological health impacts of the pandemic among the general population, health professionals and college and university students have been documented vastly [5-13]. To respond to students' mental health needs, online counselling services have 
been recommended [7,14]. Although COVID-19 mortality and morbidity curves have been flattened, the disease is still a global scare despite some countries having started to rollout mass vaccination drives.

In South Africa, by the 1st of March 2021, the government had adjusted the nationwide lockdown from Alert level 2 to Alert level 1 in terms of the Disaster Management Act of 2002 [15]. The government has also rolled-out a vaccination drive, which prioritizes, first, the vaccination of about 1.25 million healthcare workers out of a population of about 59.8 million citizens [16]. This is merely a fraction of the entire population; therefore, a majority of the population would continue being at risk of contracting COVID-19 until herd immunity is reached. On the one hand, the government continued rolling-out several relief and economic stimulus measures to mitigate against the long-term impacts of the pandemic. In spite of the government's response strategy, new COVID-19 cases are being recorded in the country, suggesting that COVID-19's health, economic and education impacts are likely to extend beyond the year 2021.

Amongst the most impacted by COVID-19 are education systems. Globally, about 215 countries had to shut down schools to contain the rapid spread of COVID-19 [17], resulting in $98 \%$ of students (which was about 14.6 million South African learners out of the total population) in those countries being out of school [18]. Diverse digital technologies (e.g., Zoom, Skype, WhatsApp, Blackboard Collaborate, radio and television) continue being employed by institutions of learning for the delivery of education remotely in order to contain the rapid spread of COVID-19 [4,19-24]. For the delivery of virtual learning, the South African government through its ministries of communication and digital technologies and basic education partnered with businesses to capacitate institutions of learning by amongst others opening some TV and radio channels for the exclusive broadcasting of live sessions facilitated by teachers. In the same vein, partnerships were entered into with established private network providers (e.g., Vodacom, MTN) to offer zero-rated applications and educational websites, including a reduced cost of data for disadvantaged students [22].

In hindsight, from the beginning of the 21st century, governments and institutions of learning ought to have realized the changes that the Fourth Industrial Revolution (4IR) was going to have on the traditional culture of student teaching and learning. To this end, plans on how to introduce online teaching technologies while capacitating and training both staff and students on their use should have been rolled-out over time. Unfortunately, compared to universities in Europe, America and some parts of Asia, most institutions of learning in Africa were caught off-guard by the pandemic because they were not prepared for eLearning as they lack the sophisticated information and communication technology (ICT) infrastructure and access to technological devices $[19,22]$. No wonder student education in rural Africa has been more impacted by the pandemic when compared to some developed parts of the world [18].

Apart from challenges regarding institutional ill-preparedness, reports have been yielding varying results about student perceptions and experiences with eLearning during the pandemic. For instance, a Slovakian study by Poláková and Klímová found that students were ready for online learning because they owned technological devices and had access to the internet at home; this was in spite of having had no prior experience with eLearning [25]. However, a comparative study with United States and German students discovered that the former group of students were more ready for online learning compared to their German counterparts [26]. When it comes to Africa, studies on student experiences are generally lacking, though some reports have suggested that remote learning may not yield positive results in rural Africa because about $82-89 \%$ of the learners did not have personal computers or access to the internet at home [18,22]. A recent study with South African students found that amidst the government's advocacy and support for online learning, rural students were indeed being left out because they lacked access to ICT infrastructure and technological devices to study whilst at home [27]. It was against this finding that the author conscientized the government on this human right violation and 
emphasized that rural students equally deserved attention as the country continues to respond to COVID-19 education impacts.

Hitherto, reports suggest that students are battling to adjust to remote learning. Online delivery of teaching and laboratory practical may not necessarily be conducive for some specialized programs (e.g., chemistry, engineering, computing, psychology, medicine) because such programs have a theoretical and practical component. With the latter not being feasible under lockdowns, the situation could overwhelm and rob the COVID-19 student cohort of an opportunity to learn certain skills compared to previous cohorts [28]. In some cases, some facilitators are also reported to be battling to adapt to the new teaching modality $[29,30]$, a situation that could also contribute to student difficulties with online learning. Factors that contribute to student adjustment difficulties to online learning are diverse and include institutional ICT ill-preparedness, student ICT ill-preparedness, socioeconomic status, work overloads, learner isolation, poor time management, homebased distractions and poor health [24,31-33].

Successful implementation of remote learning is, therefore, dependent on numerous factors, including the availability and good management of information and communication technology (ICT) infrastructure, support from institutional management, student awareness of using eLearning systems and the ability of all role players to use advanced ICT systems for learning [33,34]. With this imperative being the case, not much research has been conducted to capture students' lived experiences in South Africa regarding COVID19 's health and learning impacts including student challenges and needs [35]. Meanwhile, studies documenting the impact of the 2003 severe acute respiratory syndrome (SARS) outbreak and measures that were put in place in schools are those with Taiwanese, Singaporean and Chinese populations [36]. For African countries, which were not much impacted by the 2003 SARS, and hit later by the COVID-19 pandemic, little is known about how they have been responding to the pandemic. Africa presents with different geopolitical and socioeconomic dynamics; there is, therefore, an urgent need for research to explore how African schools and institutions of higher learning have been impacted and coping with the pandemic including establishing their needs while research efforts to finding the cure for COVID-19 are ongoing. It is against this background that, this study explored from the students' perspective, their challenges and needs pursuant to the COVID-19 nationwide lockdown in South Africa.

\section{Materials and Methods}

This report is part of a larger study aimed at developing an evidence-based psychological support program to deal with the impact of the COVID-19 pandemic on university students and personnel. A blended quantitative and qualitative approach was used to develop data collection instruments. The approach was used to maximize the strengths and minimize the weaknesses of each set of data. In the first part of the questionnaire, there were quantitative types of questions whilst the latter part comprised of qualitative open-ended questions that sought to elicit qualitative responses related to experiences during the COVID-19 lockdown, and other questions requested possible solutions to problems experienced [37]. For data collection, we utilized an electronic, self-administered, structured questionnaire. For this study, we are reporting only on the qualitative dataset based on student responses.

\subsection{Study Site}

The study was conducted at a rural-based university in South Africa. For the main study, the targeted population included the academic staff, support staff and all registered students. During the 2020 academic year, the student population at the university was estimated to be 18,701, with 2725 postgraduate students. Upon the South African government's announcement of the nationwide lockdown on the 23 of March 2020 [15], the university, like many other institutions of learning in the country, had to abandon contact lessons [18]. Although it was initially thought that the nationwide lockdown was going to 
last for 21 days, as of 26 March 2021, i.e., about a year later, the country was still on Adjusted Lockdown Alert level 1, which meant that the rural university was still not allowed to offer contact lessons or operate at full capacity $[15,18]$. At the time of closure of schools, it was not immediately clear how academic activities were going to continue because similar to many other rural institutions on the African continent [22], the university did not readily have ICT infrastructure in place for remote learning. Although the rural university had approved the use of the Blackboard platform prior to the pandemic, the platform was not being used for the delivery of interactive lectures. Realizing the potential long-term impact of the pandemic on student education, the university immediately started rolling out online crash courses intended to induct lecturers and students on the use of Blackboard for eLearning. In the same vein, the university continued to make attempts to upscale its infrastructure while availing ICT resources to the university community to optimize remote learning. Although the university has been making strides in migrating from the traditional classroom to eLearning mode, student experiences, challenges and needs remained largely undocumented. It was against this backdrop that this study was conducted in this rural setting to avail scientific data to aid the rural university's COVID-19 response strategy. The rural university is situated in the Capricorn District, which is approximately $50 \mathrm{~km}$ northeast of the capital city of Limpopo Province, Polokwane, and is categorized as one of the rural universities in the country.

\subsection{Population and Data Collection}

The population eligible for the overall study was a rural university community, i.e., its academic staff, support staff and all registered students. The current report is based on the student part of the population registered for the academic year 2020, which was sampled conveniently. This meant that if a student was not registered for the academic year 2020, they would not have had access to the questionnaire. The electronically circulated survey link prompted recipients to use their official university credentials to access the survey. This measure was embedded in the questionnaire as a quality-control measure. The survey was created and circulated using Google Forms. Once students gained access to the survey, four questions were asked to help elicit qualitative responses. Here below are the questions,

- Has the coronavirus pandemic affected your well-being in any way since the national lockdown? Yes/No

- Do you have any suggestions for the university or needs that if addressed could enhance your well-being during the lockdown?

- Do you think the coronavirus will continue affecting your well-being in any way after the lockdown? Yes/No

- Do you have any suggestions for the university or needs that if addressed could enhance your academic work and productivity after the lockdown?

The Google Forms survey link was circulated by the university marketing department to all students in the official university email database. For broader reach, the link was also shared via Facebook and WhatsApp. Data were collected over a period of 3 weeks, upon which the survey questionnaire was closed, paving way for data isolation and analysis.

\subsection{Data Analysis}

Data were analysed using a thematic method of data analysis, combining both deductive and inductive coding. The main interview questions were used as an initial coding frame. The researcher read and re-read the narrative answers provided several times to be familiar with the entire body of data before continuing with the analysis. After that, descriptive coding was undertaken, labelling relevant pieces of text and producing a list of descriptive codes. Data were put back together in new ways, making connections between codes and grouping similar codes into broader themes and subthemes. Further grouping of the emerging ideas into subthemes was carried out using constant comparison. During 
the whole coding process, regular discussions were also held with the research team to improve data trustworthiness.

\subsection{Ethical Considerations}

In the preparatory phase of the research, a research proposal was submitted to the institution's ethics committee (TREC/102/2020: PG). Subsequently, permission was sought from the University Registrar to approach the academic staff, support staff and all registered students. All 400 participants answered the qualitative open-ended questions.

Informed consent was obtained electronically from all participants before they could start responding to the online survey. The study purpose, its nature and ethical considerations were integrated online for participants' acceptance or rejection. Those who gave consent could proceed responding to the survey online, whilst those who declined were redirected out of the survey. No participant-identifying information was collected for confidentiality reasons.

\section{Results and Discussion}

The study results are presented in this section, starting with participants' demographic information in Table 1 below. Subsequently, we present and offer a discussion of qualitatively generated themes highlighting student challenges and needs grouped under five broad categories. For credibility purposes, original narrative responses from students have been retained to support the generated themes (see Appendix A).

Table 1. Participants' demographic profile.

\begin{tabular}{clcc}
\hline Variables & & Frequency & \% \\
\hline \multirow{2}{*}{ Gender } & Male & 141 & 45 \\
& Female & 171 & 55 \\
\hline \multirow{5}{*}{ Age } & $17-20$ & 104 & 32 \\
& $21-24$ & 157 & 50 \\
& $25-28$ & 34 & 11 \\
& $29-32$ & 7 & 2 \\
& $\geq 33$ & 15 & 5 \\
\hline \multirow{5}{*}{ Marital Status } & Single & 297 & 95 \\
& Married & 13 & 5 \\
& Divorced & 1 & 0 \\
& Separated & 1 & 0 \\
\hline \multirow{3}{*}{ Residential } & Urban & 23 & 7 \\
& Peri-urban & 59 & 13 \\
& Rural & 230 & 74 \\
\hline \multirow{3}{*}{ Highest level of Education } & Matric/higher education certificate & 26 & 8 \\
& 1st to 2nd level & 95 & 31 \\
& 3rd to 4th level & 112 & 36 \\
& Postgraduate & 78 & 25 \\
& Other & 1 & 0 \\
\hline
\end{tabular}

The demographic profile of the participants in Table 1 reveals that a majority of student participants were female. In their majority, the students were undergraduates with ages ranging from 21 to 24 years, which might mean that this is the group that was mostly affected by the COVID-19 lockdown because unlike postgraduate students they are studying on a full-time basis. Unsurprisingly, most students were single, and about $74 \%$ of them were mainly from rural areas. The latter could support their suggestion that they needed to be repatriated back on campus since they were affected by the lack of ICT infrastructure in rural areas [18]. 
3.1. The Suggestions Offered by Students to Enhance Their Access to Education and Well-Being in a Rural-Based University

3.1.1. The Full Opening of the University to Enhance Teaching, Learning and Research

Based on the findings, participating students highlighted that their learning has been impacted by the COVID-19 nationwide lockdown. It is for this reason that they suggested that the university needed to repatriate them back on campus to enhance their learning. Students found remote learning and studying from home frustrating and not suitable [33]. This finding is supported by the following extracts:

"Just open campus. Online learning is counterproductive. As a postgraduate student, the sooner we go back to campus, the better."

"The university must open because I'm not coping at home."

"Open campus. Online learning is not conducive."

A study conducted by Huber and Helm [24] also established that students found the new way of learning challenging during the COVID-19 lockdown. This is because the home environment is not accommodating to their academic needs compared to when they are at university and school premises [27]. It is in this regard that, apart from the COVID-19 risk, students felt that the best way to enhance their learning was for them to return to campus [35]. This, therefore, suggests that students are not coping with remote teaching and learning for it presents them with new demands $[24,28]$ while there are several learning distractions at home [31,32].

3.1.2. Development of an Academic Catch-Up Plan and Provision of Students with Consistent Academic Support

Participating students suggested to the university to come up with several teaching and learning support mechanisms to enhance their learning during and immediately after the COVID-19 lockdown. For instance, the following mechanisms were proposed:

- extension of the 2020 academic year at no extra cost to students,

- no academic work overload by lecturers in order to catch-up on the lost time,

- volunteer mentors to offer extra support to students with no access to remote learning,

- provision and timely delivery of study materials or aids,

- a need for online tutorials,

- student support with regard to using remote learning systems,

- consistent monitoring and evaluation of multimodal teaching in all faculties and departments.

Participants with these opinions stated the following:

"The academic year should be extended with no additional fees, catch up classes can be introduced, the library must operate $24 / 7$, but while at it students must not be loaded with too much of academic work."

"The university must not hurry into finishing 2020 academic year because some of us cannot cope at all."

"Support for students from academic staff is more vital than ever."

"Students will benefit from having extra academic support and having all resources (study material, support from staff, library and labs working as in exam periods) available to them to be able to complete their studies effectively."

"Yes, the university can assist students by making sure that no student is left behind this year if the process of teaching and learning is monitored at departmental, school and faculty level."

This finding further supports Haber and Helm's [24] view that in order to be considerate of students' situation, especially for those who comes from poor backgrounds, goals for formulating policies must focus on assisting such students so that they are not 
left behind with their learning activities. Alam and Tiwari [17] also support this finding by highlighting that after all countries were affected by COVID-19 they had to close schools. However, to ensure continuity in teaching and learning, remote learning programs had to employ mixed methods to ensure that students were still able to develop the relevant skills, knowledge and values that their curriculum prior to the pandemic had intended to achieve $[20,21,34]$. Indeed, student remote teaching and learning can be delivered through the blending of methods and platforms, which could include, amongst others, online learning packages, mobile applications and printed resources [20,22]. As evident from this study, there is also a need for universities to monitor and evaluate student teaching and learning across the various faculties and/or departments as a quality measure to avoid inconsistencies. More challenging for universities would always be those students from poor backgrounds and deep rural areas in terms of access to online teaching and learning $[18,22]$. This is a challenge similar to the delivery of ICT devices to staff and students during the lockdown, which the university would need to champion. In light of this finding, it therefore becomes prudent for universities to come up with remote learning support programs for students while also developing recovery plans for implementation after the nationwide lockdowns [17].

\subsubsection{Provision of Students with Efficient ICT Infrastructure for Remote Learning, Teaching and Research}

Students suggested that the university should provide them with several ICT resources (e.g., laptops, internet data) and improve online systems to enhance their remote learning. It emerged that some students had neither personal laptops nor access to the internet, which meant that they could not access online teaching whilst at home $[18,22,27,35]$. This challenge was experienced in the midst of many other learning distractions that students experienced while at home. Some students elaborated as follows about remote learning challenges, and their needs thereof:

“They must stop with virtual classes because we're encountering many problems, which are beyond our control such as network issues and bad environment for studying. Sometimes when it's raining, our rooms are leaking, and people are playing loud music outside, which interrupts our studies, and this can cause many students to fail. The painful part here is that some of the lecturers are inconsiderate in a way that they are teaching us even though not all of us have got data (10 GBs), and, we haven't received any gadgets or devices from the university for this online learning and yet they want us to participate in it."

"Become serious about the e-learning and give us the gadgets for it."

Similar challenges were noted previously with the student population from rural African settings [18]. Perhaps this is to support Alam and Tiwari [17], who have suggested that all learners must be considered so that they are enabled to access all learning opportunities anywhere and everywhere by making sure that internet access is of high quality to enable digital learning by 2021. Williams [23] concurs with the suggested strategy by students by indicating that ICT platforms and other methods are recommended to be used in order to mitigate the lost learning time caused by COVID-19 lockdown periods. Such platforms can sustain the continuity of academic activities and will also assist in ongoing learning without interruptions [23], but of course, only if all students are enabled to participate in the remote learning systems. The challenge for rural-based universities would always be to provide ICT infrastructure and devices to a large contingency of students and staff for it might be a costly exercise. However, since coronavirus interrupted the running of the economy, how the university would manage to procure and deliver such resources on time may be another challenge during the lockdown. Perhaps the government and external stakeholders could offer support to historically disadvantaged universities. Nevertheless, these are some of the challenges that disadvantaged rural-based universities may need to navigate during the pandemic, and for future preparedness, an emergency response strategy for crises similar to COVID-19 is needed. 
Although the current situation is impactful on students' learning, from the findings, it appears that some students perceive remote learning as an opportunity that the university can integrate officially as another form of multimodal teaching moving into the future. Some students remarked as follows:

"Adapt to remote learning to become the new learning or part of our learning system."

"Sticking with multimodal learning even after lockdown should make it more efficient for students to learn and not have to be in classes when it's unnecessary."

Indeed, behind every dark cloud there is a silver lining; therefore, the pandemic has not only presented itself as a challenge for most institutions of higher learning [32,34], but it has ushered in some opportunities and lessons that institutions of learning could learn from as they battle to respond to the needs of students [18].

\subsubsection{Provision of Support for the Improvement of Student's Physical and Mental Health}

Another finding was that, with students now at home, some have been unable to access their chronic health medications from the university healthcare centre. Equally, participating students made remarks-which was also evident in the quantitative aspects of the study-denoting that they have also been mentally impacted by COVID-19. It is due to these physical and mental health impacts that students felt that their well-being has since been compromised; thus, the university should have considered putting in place a support strategy to address their physical and mental healthcare needs. This finding is supported by the following extracts:

"The university can make sure that we get in touch with our lecturers and also give us access to the university health centre because that is where most of us get medication and help."

"Yes, for students who are registered with the University's health and wellness centre to collect medications for chronic conditions or please consider sending their chronic medications via courier to them, at least for the next three months or allow them to be back on campus where they can easily access their healthcare service."

"The university needs to provide therapeutic services to students, we need more social workers and psychologists help deal with COVID-19."

"The university should provide online therapy for students because some of us are struggling to study at home; learning and not being on campus makes us worry about our academics."

COVID-19 has become a global health scare, and it continues to impact negatively on the physical and mental health of health professionals, patients, students and the general population $[10,11]$. The experience of anxiety, depression and fear are some of the reported mental health impacts of the pandemic in the student population $[12,13]$. A unique finding in the present study is that the nationwide lockdown seems to have unwittingly compromised students' well-being or has put their lives at a risk $(72 \%(n=$ 226)), and some students think that the pandemic will continue to affect their well-being even after the nationwide lockdown $(62 \%(n=188))$ (see Figures 1 and 2, respectively). This finding suggests that students with chronic health conditions have been struggling to access their chronic health medications, which ordinarily they conveniently accessed from the university healthcare facilities. This is one area of importance that universities may need to pay attention to as they respond to the needs of students during the pandemic's nationwide lockdown, and for future preparedness. In addition, students need universities to avail online counselling and debriefing sessions to mitigate COVID-19 mental health impacts. Zhai and Du [14] have suggested that university counselling centres could make use of social media platforms and applications to disseminate mental-health-related information and services. Empirical evidence lends further support that online mental health services 
could bring some relief under the circumstances [7,12]. All the suggested health-support measures could enhance student's learning, research and well-being during the pandemic and immediately after the lockdown.

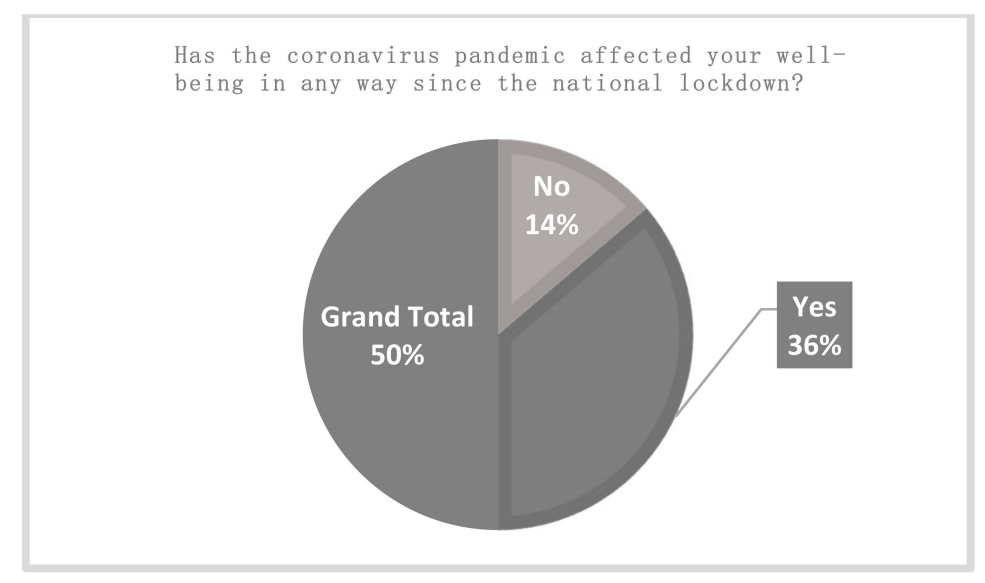

Figure 1. Students' well-being.

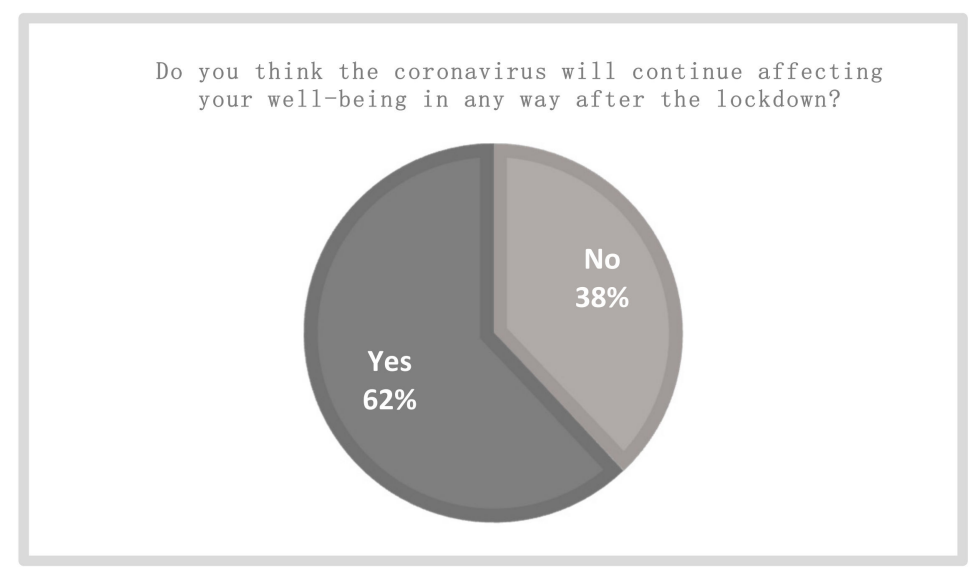

Figure 2. Students' well-being after lockdown.

\subsubsection{On-Campus COVID-19 Risk Management Plan and Future Preparedness Strategy}

With the need to be repatriated back on campus suggested, students further advised that the university needed to put in place on-campus COVID-19 risk reduction measures. Mineo has also suggested that, in order for schools to curb the spread of the virus in schools, there is a need to follow basic hygiene measures, which include repeatedly washing hands with soap and water and avoiding touching one's own face, and these self-protection measures are beneficial [38]. Previous studies have also reported that such measures could contain the fast spread of the virus in colleges and campuses, although some inconsistencies are notable in the studies $[36,39,40]$. Evaluation studies may be necessary post the implementation of such non-pharmaceutical measures to study how they would yield positive outcomes in this context. Here are extracts supporting this particular finding:

"Sanitation and social distancing should continue to be a priority as it is good for the health of students and staff."

"Masks, sanitizers, data and electronic devices should be provided to students to enhance their academic studies."

"Continue keeping health safety check in place so that everyone knows we must maintain personal hygiene."

"Introduce personal protective equipment." 
"Yes, I think the university must always have a backup plan to deal with this kind of pandemic for future purposes."

Although students have offered COVID-19 risk management measures, for future preparedness, they felt that the university needed to develop an emergency response strategy to help handle crises similar to the current pandemic. This suggestion, perhaps, comes in the wake of the pandemic having caught most institutions of learning off guard without response strategies in place. This, therefore, presents an opportunity for universities to review their learning program's future responsiveness under similar crises [19].

In this study, we qualitatively established that with the COVID-19 nationwide lockdown having impacted on students' teaching, learning and research, there is a need for the university to put in place measures to mitigate against the ongoing impacts. Participating students offered a number of strategies, which, if implemented by the university, could enhance their learning including their physical and mental well-being. In spite of the recommended strategies, to determine whether the strategies would yield positive results, postimplementation research may be imperative. However, empirical research $[17,19,20,38-40]$ supports that some of the suggested measures have yielded positive results elsewhere.

\section{Study Implications}

The SARS-COV-2 virus presented institutions of higher learning with unfamiliar challenges, yet evidence-based intervention strategies to respond to the pandemic are lacking. Rural African institutions of learning have had no prior experience of dealing with a crisis of COVID-19's magnitude, therefore, many institutions would have found themselves compromised in responding to the pandemic. In light of the pandemic still being a global threat and lockdowns still in force in most African countries, the present study findings imply that, for students in disadvantaged universities, their learning, teaching and research may continue being impacted [24,35]. This, therefore, suggests a need for rural-based African universities, with a large part of their student base from disadvantaged families, to come up with novel strategies to mitigate the ongoing COVID-19 impacts on students learning, teaching and research. This includes ways to meet their physical and mental healthcare needs. More important is the need for historically disadvantaged universities to repatriate students to campus because a majority of its student base is from rural areas where quality ICT infrastructure is lacking. Equally, some of the students do not have ICT devices such as laptops, smart phones and Wi-Fi devices to make remote learning possible [18]. Therefore, even if rural-based universities were to provide lecturers with ICT devices and improve their online systems of teaching, learning and research, this would still not suffice with some of the students lacking ICT devices and access to efficient ICT infrastructure [35]. By extension, if the universities were to go an extra mile and secure ICT devices for students [17], poor infrastructure (e.g., poor network connectivity) would still make remote learning a challenge for those students from deep rural areas. Notwithstanding the mortality and morbidity of COVID-19, however, a repatriation of students to campus appears to be the most probable solution to rural-based universities if they are to continue with teaching, learning and research that is accessible to all students. With the repatriation of students, stringent COVID-19 control measures may need to be put in place and enforced by the universities [38-40].

Furthermore, the present study findings imply that universities needed to revise their 2020 academic year calendars, and amongst others measures, offer students with extra academic support in the form of lecture support, online tutor support and timely printing and delivery of study aids to students with no access to remote learning $[17,20]$. For quality control across faculties and departments, the university may need to consistently monitor student access to remote learning during the nationwide lockdown [26]. Another implication is that COVID-19 has impacted on the physical and mental well-being of students $[12,13]$; therefore, universities needed to be cognizant of such impacts and put in place measures such as courier services to transport medications to students in need, 
while also availing online counselling sessions [14] for students who may be battling to cope with remote learning and COVID-19's mental impacts.

\section{Conclusions}

The present study established from the student population in a rural-based university, their challenges and needs during and after the nationwide coronavirus pandemic. It was established that, with the COVID-19 nationwide lockdown having impacted on students' learning, teaching and research, including health impacts, the rural-based university needed to put in place several measures to mitigate against the ongoing COVID-19 academic and health impacts. Key measures suggested included a repatriation of students to campus; a consistent student support and catch plan; improvement of ICT infrastructure for enhanced teaching, learning and research; learning, physical and mental health support and, lastly, the need for a COVID-19 risk management strategy once students are repatriated back on campus. The present study suggests that, if the proposed measures are not put in place, COVID-19 and nationwide lockdown would continue to impact negatively on student education and health. The government and private sector needed to continue offering support to rural-based universities as they try to respond to student challenges and needs during the pandemic. To determine whether the proposed measures would yield positive results post-implementation, research is needed.

\section{Limitations}

The present study was based on a small, convenient sample of students in a historically disadvantaged rural-based university. Therefore, the study is limited in two ways, which are (a) the findings do not necessarily reflect the views of all students in the present setting and (b) the findings may not be extrapolated to all historically disadvantaged Universities. Caution is therefore required when interpreting the findings, including when the suggested measures are implemented elsewhere.

Author Contributions: Conceptualisation, M.M. and T.M.M.; methodology, M.M. and T.M.M.; formal analysis, M.M., T.M.M. and P.M.; investigation, all authors; resources, M.M., J.P.M. and T.M.M.; data curation, M.M. and P.M.; preparing original draft, T.M.M., M.M. and J.P.M.; review and editing, all authors. All authors have read and agreed to the published version of the manuscript.

Funding: This research received no external funding.

Institutional Review Board Statement: The study was conducted according to the guidelines of the National Health Research Ethics Council (NHREC), and approved by the Turfloop Research Ethics Committee (TREC) (TREC/102/2020).

Data Availability Statement: The data supporting the findings of this research are available on request.

Acknowledgments: We wish to thank the university management for granting permission for the undertaking of this project. More importantly, this project could not have been possible without student participants. We truly appreciate your time. Re ya leboga!!!

Conflicts of Interest: The authors declare no conflict of interest. 


\section{Appendix A}

Table A1. Measures suggested by 2020-registered students in a rural-based university and supporting extracts.

\begin{tabular}{ll}
\hline \multicolumn{1}{c}{ Measures } & \multicolumn{1}{c}{ Supporting Participant Extracts } \\
\hline $\begin{array}{l}\text { "Opening the campus at full capacity but students shall remain in their rooms and must } \\
\text { all be screened is suggested" } \\
\text { "The university must reopen. The longer we sit around at home the worse we } \\
\text { research }\end{array}$ & $\begin{array}{l}\text { are feeling" } \\
\text { "Open university with adherence to precautionary measures" } \\
\text { "University must open so we can learn from our residents where there is Wi-Fi" }\end{array}$
\end{tabular}

“The university should first of all be considerate of family background of each student and provide necessary equipment for us students. That is, the libraries should be improved and be made more suitable for learning. More books for all modules should be available at the library".

"Put measures in place to help students study"

"Provide as much material to students in need, especially the ones in deep rural areas who find it difficult to connect with the university online facilities. Lectures should try by all means, only activity test every week, that would bring us back to our academics fully, in that way we can recover quickly"

"Offer support to students and those who are volunteering as mentors for first year students". "Provide us with all the necessary information and study materials and ensure that no student is left behind"

"If the university give us enough time to revise our work effectively and help us with

2. The development of an academic catch-up plan and provision of students with consistent academic support tutorials for almost every module and also giving us more assignments than tests will result is social distancing and reduce meeting frequently, I think all this might help in improving our academic work".

"The university must make sure that our teaching and learning takes place every time and it is monitored by the faculties"

"The university must support us and provide all the material that we need as students to keep us busy"

"The university must give us a time table in order to know where do we stand and we don't like any surprises. They must understand that we are under a lot of pressure to catch up with our studies. Then telling us what to expect will make it much easier" "Organize people to help those who are unable to attend the e-Learning"

"Please monitor the progress of each department in the university on the progress of postgraduate proposal that were long submitted before the lockdown. Please ensure that each department takes the responsibility of sending proposals to SREC, FHDC and TREC while students are still home. At least they should be able to begin with their data collection post the Lockdown and thus their studies will not be delaying. I am humbly begging of anyone responsible for receiving this information to send these suggestions to the rightful personnel. Thank you".

"Yes. Supply us with study resources for online learning, e.g., Laptop. I personally don't have one"

"Providing gadgets or hard copies of learning materials to students"

"Making online more efficient will assist and this will enhance teaching and learning in the university"

"Delivery of laptops should be done more efficiently to facilitate my ability to learn online and reduce some of my academic stress"

"Yes, the university should improve its online learning if it fails to deliver readiness for final year students to return on campus"

"I need a Laptop"

"Giving all students devices to be able to study from home"

"Distribution of the laptops to enable us to study and do assignments"

"If all students can get data and devices like laptops"

"Improving network coverage"

"They must improve their online learning" 
Table A1. Cont.

"A need for support and counselling to get back on track with our studies"

"Counselling for students who experience anxiety or are anxious with their studies, not

4. Provision of support for the improvement of student's physical and mental health sure if they will make it through this year. Emotional support services for all students would assist and go a long way"

"Provide debriefing sessions for students with good psychologist upon reopening" "Offer some psychological help for students"

"Counselling could really help"

"Continue to promote personal hygiene and students must adhere to this at all times" "Continue keeping health safety check in place so that everyone knows we must maintain personal hygiene"

"Sanitation and social distancing should continue to be a priority as it is good for the health of students and staff"

"I think the university must apply all health precautions and allow students to return to campus immediately after the lockdown so that they know they must maintain good personal hygiene"

"Introduce personal protective equipment"

5. On campus COVID-19 risk management plan and future preparedness strategy
"Masks, sanitizers, data and electronic devices should be provided to students to enhance their academic studies"

"The university to follow COVID-19 principles"

"The university has to take precautionary measures to ensure safety of students"

"The supply of mask and sanitizers"

"Prepare measures for such incidents in the future since now we have to keep moving to keep the balance, yet other individuals are being compromised"

"Academically, lecturers should not put the pressure on us by giving us a bunch of work more than we can do, because we did not plan this disaster. Planning for the future is required for such things"

"Yes, I think the university must always have a backup plan to deal with this kind of pandemic for future purposes"

\section{References}

1. World Health Organization. COVID-19 Public Health Emergency of International Concern (PHEIC). Global Research and Innovation Forum: Towards a Research Roadmap. Available online: https://www.who.int/publications/m/item/covid-19 -public-health-emergency-of-international-concern-(pheic)-global-research-and-innovation-forum (accessed on 24 February 2020).

2. South African Department of Health. Latest Confirmed Cases of COVID-19 in South Africa. South African Department of Health: The National Institute of Communicable Diseases. Available online: https:/ / www.nicd.ac.za/latest-confirmed-cases-of-covid-19 -in-south-africa/ (accessed on 24 February 2020).

3. Smith, J.A.; Judd, J. COVID-19: Vulnerability and the power of privilege in a pandemic. Health Promot. J. Austr. 2020, 31, 158-160. [CrossRef] [PubMed]

4. Mahaye, N.E. The impact of COVID-19 pandemic on South African education: Navigating forward the pedagogy of blended learning pedagogy of blended learning. Int. J. Sci. Educ. 2020, 6, 341-348.

5. Ho, C.S.; Chee, C.Y.; Ho, R. Mental health strategies to combat the psychological impact of COVID-19 beyond paranoia and panic. Ann. Acad. Med. Singap. 2020, 49, 1-3.

6. Pan, H. A glimpse of university students' family life amidst the COVID-19 virus. J. Loss Trauma 2020, 25, 594-597. [CrossRef]

7. Irawan, A.; Dwisona, D.; Lestari, M. Psychological impacts of students on online learning during the pandemic COVID-19. J. Bimbingan dan Konseling 2020, 7, 53-60. [CrossRef]

8. Simon, J.; Helter, T.M.; White, R.G.; van der Boor, C.; Łaszewska, A. Impacts of the Covid-19 lockdown and relevant vulnerabilities on capability well-being, mental health and social support: An Austrian survey study. BMC Public Health 2021, 21, 1-10. [CrossRef]

9. Mittal, S.; Singh, T. Gender-based violence during COVID-19 pandemic: A mini-review. Front. Glob. Women's Health 2020, 10, 020359.

10. Luo, M.; Guo, L.; Yu, M.; Wang, H. The psychological and mental impact of coronavirus disease 2019 (COVID-19) on medical staff and general public-A systematic review and meta-analysis. Psychiatry Res. 2020, 292, 113190. [CrossRef]

11. Li, S.W.; Wang, Y.; Yang, Y.Y.; Lei, X.M.; Yang, Y.F. Analysis of influencing factors of anxiety and emotional disorders in children and adolescents during home isolation during the epidemic of novel coronavirus pneumonia. Chin. J. Child Health 2020, 28, 1-9.

12. Cao, W.; Fang, Z.; Hou, G.; Han, M.; Xu, X.; Dong, J.; Zheng, J. The psychological impact of the COVID-19 epidemic on college students in China. Psychiatry Res. 2020, 287, 112934. [CrossRef] 
13. Odriozola-González, P.; Planchuelo-Gómez, Á.; Irurtia, M.J.; de Luis-García, R. Psychological effects of the COVID-19 outbreak and lockdown among students and workers of a Spanish university. Psychiatry Res. 2020, 1, 290.

14. Zhai, Y.; Du, X. Addressing collegiate mental health amid COVID-19 pandemic. Psychiatry Res. 2020, 288, 113003. [CrossRef]

15. South African Government Gazette. Regulations Issued in Terms of Section 27 of the Disaster Management Act, 2002. Government Gazette: Disaster Management. Available online: https://www.gov.za/sites/default/files/gcis_document/202004/43258rg110 98gon480s.pdf (accessed on 29 April 2020).

16. South African Department of Health. What Does South Africa's COVID Vaccine Roll-Out Plan Say? The National Institute of Communicable Diseases. Available online: https:/ / sacoronavirus.co.za/2021/01/12/what-does-south-africas-covid-vaccineroll-out-plan-say/ (accessed on 9 March 2021).

17. Alam, A.; Tiwari, P. "Putting the 'Learning' Back in Remote Learning: Policies to Uphold Effective Continuity of Learning through COVID-19". Office of Global Insight and Policy, Issue Brief. UNICEF. In Education and COVID-19 Pandemic; Daniel, S.J., Ed.; PubMed Central, 2020; pp. 1-6. Available online: http:/ / doi.org/10.1007/s11125-020-09464-3 (accessed on 25 January 2021).

18. United Nations Education Scientific and Cultural Organization (UNESCO). COVID-19 Educational Disruption and Response. Beirut: UNESCO. Available online: https:/ / en.unesco.org/covid19/educationresponse (accessed on 29 April 2020).

19. Asunka, S. Online Learning in Higher Education in Sub-Saharan Africa: Ghanaian University students' experiences and perceptions. Int. Rev. Res. Open Dis. 2008, 9, 1-24. [CrossRef]

20. Kimenyi, E.; Otieno, J.; Kaye, T. Building effective COVID-19 Education Response Plans: Insights from Africa and Asia. EdTech Hub 2020, 15, 1-27.

21. Lin, R.J.; Lee, T.H.; Lye, D.C. From SARS to COVID-19: The Singapore journey. Med. J. Aust. 2020, 212, 497-502. [CrossRef]

22. Mhlanga, D.; Moloi, T. COVID-19 and the Digital Transformation of Education: What Are We Learning on 4IR in South Africa? Educ. Sci. 2020, 10, 180. [CrossRef]

23. Williams, K. “COVID-19 Exposes Education System Achilles Heels: Insights Leading Voices on Todays' Topics" Leland: Creative. 2020. Available online: https:/ /www.creativeassociatesinternational.com/insights/covid-19-exposes-education-systemsachilles-heel/ (accessed on 23 September 2020).

24. Huber, S.G.; Helm, C. COVID-19 and schooling: Evaluation, assessment and accountability in times of crises-reacting quickly to explore key issues for policy, practice and research with the school barometer. Educ. Assess. Eval. Acc. 2020, 32, 237-270. [CrossRef]

25. Poláková, P.; Klímová, B. The Perception of Slovak Students on Distance Online Learning in the Time of Coronavirus-A Preliminary Study. Educ. Sci. 2021, 11, 81. [CrossRef]

26. Küsel, J.; Martin, F.; Markic, S. University Students' Readiness for Using Digital Media and Online Learning-Comparison between Germany and the USA. Educ. Sci. 2020, 10, 313. [CrossRef]

27. Dube, B. Rural Online Learning in the Context of COVID-19 in South Africa: Evoking an Inclusive Education Approach. REMIE 2020, 10, 135-157. [CrossRef]

28. Gamage, K.A.A.; Wijesuriya, D.I.; Ekanayake, S.Y.; Rennie, A.E.W.; Lambert, C.G.; Gunawardhana, N. Online Delivery of Teaching and Laboratory Practices: Continuity of University Programmes during COVID-19 Pandemic. Educ. Sci. 2020, 10, 291. [CrossRef]

29. Cassibba, R.; Ferrarello, D.; Mammana, M.F.; Musso, P.; Pennisi, M.; Taranto, E. Teaching Mathematics at Distance: A Challenge for Universities. Educ. Sci. 2021, 11, 1. [CrossRef]

30. Schuck, R.K.; Lambert, R. “Am I Doing Enough?” Special Educators' Experiences with Emergency Remote Teaching in Spring 2020. Educ. Sci. 2020, 10, 320. [CrossRef]

31. Adedoyin, O.B.; Soykan, E. Covid-19 pandemic and online learning: The challenges and opportunities. Interact. Learn. Environ. 2020, 1-13. [CrossRef]

32. Heng, K.; Sol, K. Online Learning during COVID-19: Key Challenges and Suggestions to Enhance Effectiveness. Cambodian Education Forum. Available online: https: / cefcambodia.com/2020/12/08/online-learning-during-covid-19-key-challenges-andsuggestions-to-enhance-effectiveness / (accessed on 26 March 2020).

33. Lassoued, Z.; Alhendawi, M.; Bashitialshaaer, R. An exploratory study of the obstacles for achieving quality in distance learning during the COVID-19 pandemic. Educ. Sci. 2020, 10, 232. [CrossRef]

34. Alqahtani, A.Y.; Rajkhan, A.A. E-learning critical success factors during the covid-19 pandemic: A comprehensive analysis of e-learning managerial perspectives. Educ. Sci. 2020, 10, 216. [CrossRef]

35. Anifowoshe, O.; Aborode, A.T.; Ayodele, T.I.; Iretiayo, R.A.; David, O.O. Impact of COVID-19 on Education in Sub-Saharan Africa. Preprints 2020. Available online: https:/ / doi.org/10.20944/preprints202007.0027.v1 (accessed on 23 August 2020).

36. Viner, R.M.; Russell, S.J.; Croker, H.; Packer, J.; Ward, J.; Stansfield, C.; Mytton, O.; Bonell, C.; Booy, R. School closure and management practices during coronavirus outbreaks including COVID-19: A rapid systematic review. Lancet Child Adolesc. Health 2020, 4, 397-404. [CrossRef]

37. Fetters, M.D.; Curry, L.A.; Creswell, J.W. Achieving integration in mixed methods designs-Principles and practices. Health Serv. Res. 2013, 4, 2134-2156. [CrossRef]

38. Mineo, L. "How to Reduce the Spread of Coronavirus". Harvard University: The Harvard Gazette. Available online: https: / / news.harvard.edu/gazette/story/2020/03/preventing-the-spread-of-coronavirus-starts-with-basic-hygiene (accessed on 5 March 2020). 
39. Cowling, B.J.; Ali, S.T.; Ng, T.W.Y.; Tsang, T.K.; Li, J.M.C.; Fong, M.W.; Liao, Q.; Kwan, M.Y.W.; Lee, S.L.; Chiu, S.S.; et al. Impact assessment of non-pharmaceutical interventions against coronavirus disease 2019 and influenza in Hong Kong: An observational study. Lancet Public Health 2020, 5, 279-288. [CrossRef]

40. Ferguson, N.M.; Laydon, D.; Nedjati-Gilani, G.; Imai, N.; Ainslie, K.; Baguelin, M.; Bhatia, S.; Boonyasiri, A.; Cucunubá, Z.; Cuomo-Dannenburg, G.; et al. Report 9: Impact of Non-Pharmaceutical Interventions (NPIs) to Reduce COVID-19 Mortality and Healthcare Demand. Available online: https:/ / www.researchgate.net/publication/342182508_Report_9_Impact_of_nonpharmaceutical_interventions_NPIs_to_reduce_COVID-19_mortality_and_healthcare_demand (accessed on 25 February 2021). 